\title{
Política de atenção à fissura labiopalatina: a emergência do Centrinho de Salvador, Bahia
}

I ' Sônia Cristina Lima Chaves, ${ }^{2}$ Laedson Carlos Moreira da Silva,

\author{
${ }^{3}$ Ana Maria Freire de Lima Almeida I
}

Resumo: Analisou-se a emergência do enfrentamento das fissuras labiopalatinas na Bahia entre 1990 e 2000, em estudo exploratório da emergência do Centro de Reabilitação de Anomalias Craniofaciais da Bahia, utilizando a análise do espaço social, dos agentes e seus capitais, segundo Bourdieu (2014). Foram conduzidas entrevistas semiestruturadas, análises de relatórios e de documentos oficiais. $\mathrm{O}$ estudo revelou que a criação do "Centrinho" em Salvador-BA, resultou de condiçôes de possibilidade de financiamento de alta complexidade, associado à conjunção de disposições distintas dos diferentes agentes fundadores. Nesse espaço, coexistem especialistas na reabilitação e disputas sobre a definição do que é a atenção integral à pessoa com fissura labiopalatina.

> Palavras-chave: fenda labial; fenda palatina; política de saúde; história da saúde; saúde pública.

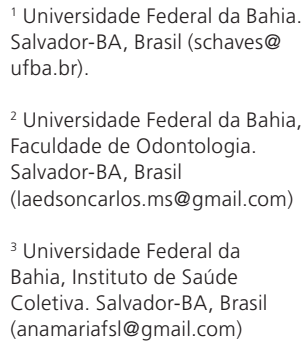

1 Universidade Federal da Bahia. Salvador-BA, Brasil (schaves@ ufba.br).

${ }^{2}$ Universidade Federal da Bahia, Faculdade de Odontologia. Salvador-BA, Brasil

(laedsoncarlos.ms@gmail.com)

${ }^{3}$ Universidade Federal da Bahia, Instituto de Saúde Coletiva. Salvador-BA, Brasi (anamariafs|@gmail.com)

Recebido em: 07/07/2015 Aprovado em: 31/03/2016 
As fissuras labiopalatinas são alterações faciais de origem embriológica, que resultam da falta de fusão dos processos nasais mediais entre si, e desses com os processos maxilares (MELGAÇO et al., 2002). A etiologia está associada a fatores genéticos (consanguinidade, mulheres com idade avançada e herança genética), sobretudo os relacionados ao próprio indivíduo (mutaçôes e polimorfismo). A hipótese é que os fatores genéticos interagem com fatores ambientais (a carência nutricional, o etilismo e o tabagismo), desenvolvendo as fissuras, principalmente nos portadores de polimorfismos genéticos que demonstram fragilidade em relação a esses fatores (SOUZA-FREITAS et al., 2004; BOYLE et al., 2010).

Constituem a malformação craniofacial mais comum da regiāo orofacial de humanos recém-nascidos vivos, com prevalência maior que a síndrome de Down (MARTELLI et al., 2010; AQUINO et al., 2011). A prevalência mundial é em torno de um caso para cada 650 indivíduos, ou seja, 1,53 por mil nascidos vivos (WEHBY; CASSELL, 2010). No Brasil, estudos apontam que a prevalência varia de 0,19 a 1,54 por mil nascidos vivos (DI NINNO et al., 2011). Etnicamente varia de acordo com o grupo humano (africanos: 0,3; europeus: 1,3; asiáticos: 2,1; índios norte-americanos: 3,6). Parece haver predominância no sexo masculino, do tipo unilateral e pelo lado facial esquerdo (MARTELLI et al., 2010; DI NINNO et al., 2011).

Os custos da atenção à saúde nessa área são elevados no mundo e também no Brasil, chegando a atingir acentuados níveis de complexidade (HOROVITZ et al., 2005; WEHBY; CASSELL, 2010), pela necessidade da reabilitação, que inclui várias intervençôes cirúrgicas ao longo da vida e acompanhamento do crescimento e desenvolvimento facial e fonoaudiológico. As intervençôes para o enfrentamento deste problema no mundo são realizadas em centros especializados ou hospitais públicos e privados, a depender da política de saúde de cada país. Existem organizações internacionais não governamentais, presentes em 87 países, desenvolvendo uma rede de parcerias para intervir nesse tipo de anomalia, que estão ligadas à Rede Global de Pesquisa em Saúde Materno-Infantil, criada em 1999, numa parceria entre a Fundação Melinda e Bill Gates, o National Institute of Health (NIH) e o National Institute of Children and Human Development (NICHD), segundo HRAC-USP (2004). Alguns estudos apontam que os mutirões médicos desenvolvidos por essas 
organizações não governamentais podem auxiliar no enfrentamento parcial do problema (MURRAY et al., 1997; MENDOZA, 2009).

No Brasil, o enfrentamento se iniciou em 1967, quando o primeiro Centro de Reabilitação de Anomalias Craniofaciais (CRAC) foi criado em Bauru, São Paulo. Hoje existem no Brasil 28 centros de atenção às anomalias orofaciais, a maioria vinculada a instituições hospitalares e entidades filantrópicas (MONLLEÓ; GIL-DA-SILVA-LOPES, 2006; BRASIL, 2016), como é o caso do centro localizado na Bahia.

A Bahia apresenta alta prevalência de casos de fissura labiopalatina em relação aos dados de prevalência mundial e nacional. Em 2001, apresentou 1,86 caso notificado a cada mil nascidos vivos. Em 2005, foram 2,33 e em 2010 foram 4,1 por mil nascidos vivos (BRASIL, 2013). Para seu enfretamento no estado foi criado, no ano de 1997, o Centro de Reabilitação de Anomalias Craniofaciais (Centrinho de Salvador-BA), vinculado às Obras Sociais Irmã Dulce (OSID). A OSID tem sua origem nos anos 1949, quando Irmã Dulce, a "Bem-aventurada Dulce dos Pobres”, beatificada pela Igreja Católica em 2011, criou um abrigo para doentes resgatados das ruas de Salvador e iniciou então a consolidação da instituição (OSID, 2014).

Os estudos revisados descrevem o surgimento e desenvolvimento desses centros de referência para o tratamento da pessoa com fissura labiopalatina no Brasil (HRAC-USP, 2004; MONLLEÓ; GIL-DA-SILVA-LOPES, 2006). Entretanto, as razões da sua emergência nas conjunturas específicas são pouco investigadas. Há ausência de trabalhos que tratem sobre os agentes, as instituições e as razões que conduziram à implementaçãode uma resposta formalizada do Estado no Brasil e na Bahia, em particular. Cabe investigar as condiçôes de possibilidade que permitiram a origem do centro em uma organização não estatal e não ligada diretamente a uma universidade, como é o caso do modelo baiano.

No presente estudo, considerou-se política de saúde como ação do Estado através de uma resposta social organizada frente a necessidades de saúde demandadas por determinados grupos. Essa resposta social ocorre no interior de espaços sociais, onde o objetivo é compartilhado pelos agentes engajados na luta. O conceito de espaço social se refere a um espaço de relações de força entre agentes e instituições, engajados em lutas concorrentes em torno de um objetivo comum (PINELL, 2011) - neste caso específico, o enfrentamento 
da fissura labiopalatina. Dentro do espaço social "em defesa da pessoa com fissura labiopalatina", articulam-se agentes e instituições de diversos campos, especialmente do campo médico, científico, religioso, burocrático e político, além de um espaço associativo, engajado na luta pela organização da resposta ao agravo no Brasil. O campo é um espaço social com maior autonomia relativa, com leis próprias, onde os agentes nele engajados compartilham disposiçôes comuns de percepção e apreciação do mundo social, as quais foram incorporadas na história desse campo em particular (BOURDIEU, 1996).

Por outro lado, esses agentes oriundos de diferentes campos possuem diversas espécies de capital, como acúmulos, energia social, que são as principais formas de poder utilizadas pelos mesmos ao interior dos espaços de luta (PINELL, 2011; BOURDIEU, 2014). Destacam-se o capital cultural, constituído por um conjunto de bens simbólicos relacionados aos conhecimentos incorporados via origem familiar e capital escolar com os efeitos dos títulos outorgados pelo Estado, e diferentes outros tipos de capital específico, como o capital médico, científico, burocrático do tipo administrativo, político e o religioso. Todos esses são tipos de acúmulo ao interior de seus respectivos campos que podem ser convertidos em capital simbólico, que consiste na transformação de uma espécie qualquer de capital em reconhecimento legítimo pelos demais agentes no espaço (BOURDIEU, 1996; PINELL, 2011). Assim, a estrutura desse espaço social de luta em defesa da pessoa com fissura labiopalatina, onde as diversas instituições e agentes engajados pertencem a diferentes campos, com capitais acumulados desigualmente e interesses em jogo, pode resultar em formas distintas de emergência e implementação da política, como resposta social organizada.

Nesse sentido, o objetivo deste estudo foi analisar, numa perspectiva sociológica das políticas de saúde (PINELL, 2011), a emergência do Centro de Reabilitação de Anomalias Craniofaciais do Hospital Santo Antônio, em Salvador-BA, vinculado às Obras Sociais Irmã Dulce (OSID), conhecido como "Centrinho", como intervenção pública de caráter filantrópico. Além disso, buscou-se caracterizar o processo histórico e as condições de possibilidade da resposta social às fissuras labiopalatinas, identificar os principais agentes fundadores do Centrinho, bem como suas trajetórias e inserção em distintos campos sociais, apontando possíveis questôes em disputa nesse espaço social no Brasil. 
Este foi um estudo exploratório, sócio-histórico, sobre a emergência de uma política pública para enfrentamento de um agravo de saúde no período entre 1990 e 2000, através da análise do caso do Centro de Reabilitação de Anomalias Craniofaciais do Hospital Santo Antônio na Bahia (Centrinho), tendo como base algumas categorias analíticas do referencial teórico de Pierre Bourdieu (1996; 2014), especialmente nos conceitos de campo e espaço social e os diferentes tipos de capital dos agentes. Os estudos de Patrice Pinell (2011), de análise sociológica de políticas públicas de saúde, auxiliaram na abordagem dos “espaços de luta”. Cabe destacar que este estudo não pretendeu abordar todas as categorias analíticas do sociólogo francês e tratou de fatos recentes na conjuntura pós-constituinte brasileira.

Nesse espaço social os agentes e instituições possuem interesses específicos, onde o habitus é compartilhado, comum entre os mesmos. $\mathrm{O}$ habitus, segundo Bourdieu (1996; 2014), é um sistema de disposiçôes socialmente incorporadas que produz modos de perceber, fazer e pensar, que leva o agente a agir de determinada forma em uma circunstância dada, refletindo a tomada de posição no espaço de luta.

O campo burocrático é o espaço onde os agentes do Estado formulam as políticas e o discurso do universal como uma referência obrigatória aos valores de interesse ao bem comum, onde o "interesse pelo desinteresse" é recompensado por ganhos simbólicos, de reconhecimento (BOURDIEU, 2014). O campo religioso é aquele onde a ideia de caridade é estimulada e vista como a ação de amparo gratuito ao próximo (principalmente os desvalidos) em nome da salvação ou de Deus, feito de uma pessoa para outra sem associação ou intermediário (SOUZA; BARRETO, 2011). Assim, as disposições religiosas dos agentes situados no campo são inculcadas e podem existir de forma inconsciente, o habitus, influenciando as tomadas de posição nesse espaço de luta (BOURDIEU, 1996).

Para analisar os capitais dos agentes e identificar os indivíduos do processo de fundação do Centrinho, foram realizadas entrevistas semiestruturadas com os agentes que participaram do projeto e sua implementação inicial $(n=6)$, de acordo com a técnica da bola de neve (quadro 1). O roteiro de entrevista incluiu as categorias analíticas prévias como origem social, tipos de capital dos agentes (cultural, científico, médico, burocrático do tipo administrativo e simbólico), 
participação nos distintos campos (especialmente político, médico, burocrático e religioso), condições de possibilidade histórica, incluindo os antecedentes da política e visão sobre o agravo, estratégias de tratamento e possibilidades de intervenção. As principais perguntas no roteiro foram relacionadas a formação e trajetória profissional, origem familiar (escolaridade e profissão dos pais e avós), participação política de qualquer natureza ou na causa das pessoas com fissura labiopalatina.

Num segundo momento, perguntou-se a cada um deles sobre como e quando se iniciou o trabalho com fissura labiopalatina, como o agente compreendia a história do serviço na Bahia e a identificação dos principais fundadores, as formas de financiamento passada e atual do serviço. As questôes relacionadas ao trabalho multiprofissional, uso de protocolos e suporte material e instrumental para desenvolvimento das atividades de reabilitação dos pacientes com fissura labiopalatina também foram incluídas. O processo histórico da resposta social brasileira às fissuras labiopalatinas nesse período foi caracterizado a partir da busca nos documentos-base do Ministério da Saúde e outros artigos e teses publicados sobre o tema.

As entrevistas foram gravadas e transcritas. Todas as entrevistas foram realizadas por um único pesquisador. Foram analisados os curriculos Lattes disponíveis dos agentes, com o objetivo de construir a trajetória profissional, aferir seus distintos capitais, especialmente o científico, burocrático do tipo administrativo e médico e a posição ocupada à época da fundação do Centrinho, além dos documentos institucionais e reportagens de jornais do período da emergência do serviço (1996 até 1999). Foi conduzida análise temática de conteúdo das entrevistas e demais documentos à luz das categorias analíticas apresentadas no marco teórico, incluindo a caracterização do espaço de luta na origem dessa resposta na Bahia, as condições de possibilidade históricas, os distintos capitais dos agentes fundadores, suas disposições, posição e tomadas de posição em torno da emergência do serviço.

O estudo foi aprovado pelo Comitê de Ética em Pesquisa do Instituto de Saúde Coletiva da Universidade Federal da Bahia (registro no 475.555-CEP-ISC). Todos os entrevistados assinaram o Termo de Consentimento Livre e Esclarecido, com aprovação da divulgação do seu nome e conteúdo das entrevistas, e obtevese também a anuência institucional. 
Quadro 1. Relação de agentes entrevistados, especialidade e participação no espaço social na emergência da Centrinho de Salvador-BA, 1997

\begin{tabular}{|c|c|c|c|c|}
\hline \multirow[t]{2}{*}{ Agente } & \multirow{2}{*}{$\begin{array}{l}\text { Formaçáo profissional e } \\
\text { cargo ocupado }\end{array}$} & \multicolumn{2}{|c|}{ Participação } & \multirow{2}{*}{$\begin{array}{c}\text { Currículo } \\
\text { Lattes }\end{array}$} \\
\hline & & Fundadores & $\begin{array}{c}\text { Implementação } \\
\text { inicial }\end{array}$ & \\
\hline $\begin{array}{l}\text { Maria Conceição } \\
\text { Freitas }\end{array}$ & $\begin{array}{l}\text { cirurgiã-dentista } \\
\text { ortodontista }\end{array}$ & NÃO & SIM & SIM \\
\hline Maria Rita Veloso & $\begin{array}{l}\text { técnica assistente } \\
\text { administrativa }\end{array}$ & NÃO & SIM & NÃO \\
\hline Paulo Plessin & médico cirurgião plástico & NÃO & SIM & SIM \\
\hline Roberto Azevedo & $\begin{array}{l}\text { cirurgião-dentista } \\
\text { bucomaxilofacial }\end{array}$ & NÃO & SIM & SIM \\
\hline Taciano Campos & $\begin{array}{l}\text { médico cirurgião geral/ } \\
\text { direção médica }\end{array}$ & SIM & SIM & NÃO \\
\hline Túlio Azevedo & $\begin{array}{l}\text { médico anestesista/ } \\
\text { coordenador }\end{array}$ & SIM & SIM & SIM \\
\hline
\end{tabular}

Fonte: elaboração própria.

\section{Resultados}

\section{Os agentes fundadores e seus distintos capitais}

Os agentes reconhecidos como fundadores do Centrinho da Bahia foram Túlio Azevedo, Taciano Campos e Maria Rita Lopes Pontes.

Túlio Azevedo é reconhecido pelos entrevistados como o principal articulador e fundador do Centrinho de Salvador na Bahia. Médico anestesista, foi integrante de organizações estudantis durante a ditadura militar, filiado ao Partido dos Trabalhadores (PT) desde 1988. De família tradicional do interior da Bahia, em 1990 formou-se em Medicina pela Escola Bahiana de Medicina e Saúde Pública (EBMSP), na qual se tornou professor. Fez pós-graduação em São Paulo, onde conheceu em 1996 o "Centrinho" de Bauru-SP, e seu fundador José Alberto de Souza-Freitas. Na mesma época, já como membro das Obras Sociais Irmã Dulce (OSID), Túlio Azevedo conheceu o Centro de Reabilitação e Prevenção de Deficiências (CRPD), e um fato marcante em sua vida ocorreu, conforme relato:

[...] esqueceram propositadamente, talvez por saberem que eu era médico, uma criança com menos de um ano na carroceria do meu carro. Eu abri e vi que era uma criança fissurada. Já era grandinha, deveria ter uns oito meses. Era uma fissura 
labial, não era palatal e era unilateral. Aí tudo foi efervescendo, as minhas ideias de realmente montar o Centrinho. [...]. (Túlio Azevedo, médico e coordenador do Centrinho à época da fundação).

Esse agente possuía um conjunto de disposições políticas e alto capital global acumulado (científico, médico e político), que lhe permitiram estabelecer uma rede de relações e ter protagonismo no processo de implantação dessa instituição de caráter filantrópico na Bahia, conforme relatou durante a entrevista:

O Centrinho foi fundado e se manteve lá na OSID e não em outro lugar, porque eu era docente da Escola Bahiana de Medicina do ponto de vista acadêmico, e profissional trabalhava na Irmã Dulce, era onde estavam meus dois mundos. Como eu tive essa oportunidade de conhecer Bauru e fazer o mestrado na UNESP, eu fiz uma rede de relacionamento muito forte em Bauru-SP. Mas o Taciano também é o braço político das Obras com a secretaria. Evidente também que o nome Irmã Dulce ajudou. [...]. (Túlio Azevedo, médico e coordenador do Centrinho à época da fundação).

Taciano Campos, o articulador, foi "braço direito" de Irmã Dulce e também de Maria Rita Lopes Pontes, atual superintendente das Obras Sociais Irmã Dulce (OSID). Graduou-se em Medicina pela Universidade Federal da Bahia em 1964, fez residência em cirurgia geral, tendo falecido em 2015. Quando ainda era residente em cirurgia, colaborou com a OSID por influência de seu preceptor, Gerson Mascarenhas, diretor da instituição à época da ditadura militar, posteriormente afastado dessa função, que Taciano Campos assumiu em 1972, ainda que sem disposições para o campo político. A partir dos argumentos de Túlio Azevedo, de que o serviço para a reabilitação da fissura labiopalatina seria inovador em todo o Norte e Nordeste, Taciano Campos foi quem apresentou a proposta à superintendente da instituição.

Graças ao Túlio foi um casamento fácil a parceria entre Bauru-SP e a OSID [...] O Túlio foi o pai da criança. (Taciano Campos, diretor médico do Hospital à época da fundação do Centrinho).

Observa-se que o agente fundador Taciano Campos possuía um capital global acumulado burocrático do tipo administrativo, filantrópico do tipo religioso e grande capital simbólico ao interior da instituição, que permitiu sua intermediação para aprovação da implantação do serviço por parte da superintendente.

A criação do Centrinho também se relacionou ao fato de a OSID já ter, à época, interesse em ofertar serviço de alta complexidade, pela melhor remuneração no Sistema Único de Saúde (SUS). Isto poderia ocorrer pela 
cirurgia de queiloplastia do palato e outros procedimentos nesse grupo, desde 1993(BRASIL, 1993; BRASIL, 1994).

Maria Rita se propôs a olhar o serviço e gostou muito. Então se encaminhou uma parceria com Bauru, que é referência mundial [...]. Então fizemos isso, o pessoal de Bauru veio para Salvador fazer cirurgias e o pessoal daqui ajudava. Depois, dois profissionais daqui foram para Bauru treinar lá. (Taciano Campos, diretor médico do Hospital à época da fundação do Centrinho).

A agente fundadora, Maria Rita Lopes Pontes, sobrinha de Irmã Dulce e superintendente da organização, possuía um alto capital global acumulado (filantrópico, simbólico e administrativo). Foi a partir da sua aprovação e da parceria iniciada com o Centrinho de Bauru-SP, que ocorreu a fundação do Centrinho baiano em 1997. O serviço passou a funcionar de forma improvisada no Centro de Reabilitação e Prevenção de Deficiências (CRPD) da OSID, tendo Túlio Azevedo como primeiro diretor.

No principal relatório que garantiu o credenciamento para a alta complexidade, pode-se observar a descrição dos casos clínicos, mas também uma transmissão de forte carga emotiva denotada pela exaltação do altruísmo e capital simbólico representado por Irmã Dulce. Em uma das páginas do relatório, faz-se referência à frase "ninguém me quis, alguém me aceitou", que reforça o papel social e religioso da instituição.

Concretamente, o financiamento foi garantido em parte com recursos do Banco Nacional de Desenvolvimento Econômico e Social (BNDES), através do convênio do Sistema Integrado de Administração Financeira do Governo Federal (SIAFI) no 331862 (6915/97), da ordem de $\mathrm{R} \$ 53.614,13$, para aquisição de equipamentos, e do Convênio SIAFI no 328310 (4099/97), da ordem de R\$ 120.513,24, para aquisição de material didático e reforma. Outro financiamento ocorreu entre 1998 e 1999, proveniente de convênio entre a Fundação Banco do Brasil e a OSID, que custeou a construção do novo espaço sede atual do Centrinho Salvador-BA.

\section{As condições históricas de possibilidade e as redes de relações}

$\mathrm{O}$ estudo revelou que a principal condição de possibilidade do nascimento do serviço voltado para as anomalias orofaciais na Bahia esteve relacionada à formulação da lei que deu origem ao SUS. A Lei no 8080/90 e a Lei Orgânica 
da Assistência Social (LOAS) possibilitaram iniciativas em prol do "espaço social em defesa da pessoa com FLP”, como, por exemplo, a incorporação da fissura labiopalatina (FLP) na alta complexidade pelo SUS, a criação de mecanismos de pagamento para correção de FLP e a realização de implante dentário ósseointegrado na tabela do Sistema de Informaçōes Hospitalares (SIH/SUS) em 1993 (BRASIL, 1990; 1993a; 1993b). Os principais fatos estão resumidos no quadro 2.

Quadro 2. Principais fatos no campo burocrático, científico e espaço associativo com relação à política de enfrentamento da fissura labiopalatina com provável repercussão na fundação do Centrinho de Salvador-BA

\begin{tabular}{|c|c|c|c|c|c|}
\hline 1990 & 1993 & $1994 / 95$ & 1997 & 1999 & 2000 \\
\hline $\begin{array}{l}\text { Lei 8080/90 } \\
\text { (dispóe sobre } \\
\text { o Sistema } \\
\text { Único de } \\
\text { Saúde - SUS) }\end{array}$ & $\begin{array}{l}\text { Lei no } 8.742 / 93 \\
\text { (Lei Orgânica da } \\
\text { Assistência Social) } \\
\text { Decreto no } 914 \\
\text { (Política Nacional } \\
\text { para Integração } \\
\text { das Pessoas com } \\
\text { Deficiência) } \\
\text { Incorporação } \\
\text { do tratamento } \\
\text { de fissura } \\
\text { labiopalatina } \\
\text { na Alta } \\
\text { Complexidade } \\
\text { e mecanismos } \\
\text { de pagamento } \\
\text { de correções de } \\
\text { fissuras na tabela } \\
\text { do SIH/SUS }\end{array}$ & $\begin{array}{l}\text { Normas de } \\
\text { credenciamento } \\
\text { para a prestação } \\
\text { de serviços de } \\
\text { reabilitação } \\
\text { de pessoas } \\
\text { com fissura } \\
\text { labiopalatina } \\
\\
\text { I Encontro } \\
\text { Nacional de } \\
\text { Associaçôes } \\
\text { de Pais e } \\
\text { Portadores } \\
\text { de Lesões } \\
\text { Labiopalatais } \\
\text { e IV Encontro } \\
\text { Nacional de } \\
\text { Coordenadores } \\
\text { (Rede Profis) }\end{array}$ & $\begin{array}{l}\text { Fundação do } \\
\text { Centrinho de } \\
\text { Salvador-BA } \\
\text { II Encontro } \\
\text { Nacional de } \\
\text { Associações e } \\
\text { Coordenadores } \\
\text { de Portadores } \\
\text { de Lesões } \\
\text { Lábio-palatais } \\
\text { e Deficiência } \\
\text { Auditiva (Rede } \\
\text { Profis) } \\
\text { Eurocleft } \\
\text { Project }\end{array}$ & $\begin{array}{l}\text { Consolidação } \\
\text { da Rede de } \\
\text { referência no } \\
\text { tratamento de } \\
\text { deformidades } \\
\text { craniofaciais } \\
\text { (RRTDCF) } \\
\text { Implante } \\
\text { coclear no SUS } \\
\text { Decreto } \\
\text { no } 3.298 \\
\text { (regulamenta a } \\
\text { Lei no } 7853 / 89- \\
\text { Integração } \\
\text { da pessoa } \\
\text { portadora de } \\
\text { deficiência) } \\
\text { Lei 9.790/99 } \\
\text { (dispóe sobre } \\
\text { Organizações } \\
\text { da Sociedade } \\
\text { Civil de } \\
\text { Interesse } \\
\text { Público). }\end{array}$ & $\begin{array}{l}\text { Publicação do } \\
\text { documento } \\
\text { Global } \\
\text { Strategies to } \\
\text { Reduce the } \\
\text { Health-care } \\
\text { Burden of } \\
\text { Craniofacial } \\
\text { Anomalies } \\
\text { (WHO,2000) }\end{array}$ \\
\hline
\end{tabular}

Fontes: Legislação Brasileira, WHO/OMS, organizações não governamentais e site da rede Profis (disponível em: www.redeprofis.com.br). 
Em 1994, foram instituídas as normas de credenciamento para as instituições que prestavam o serviço de reabilitação de pessoas com fissuras labiopalatinas (BRASIL, 1994); em 1999, iniciou-se a consolidação da Rede de Referência no Tratamento de Deformidades Craniofaciais (RRTDCF) (BRASIL, 1999a). A maioria dos centros de referência do país foi criada a partir de 1993, após a publicação da portaria que introduziu os procedimentos de alta complexidade para o tratamento de pessoas com fissuras na tabela do SIH/SUS (BRASIL, 1993a). Atualmente há 28 Centros de Reabilitação de Anomalias Craniofaciais (CRAC), e esses serviços com financiamento público estão presentes nas cinco regiōes do país (BRASIL, 2016).

Estudo de Monlleó e Gil-da-Silva-Lopes (2006) apontou que 19 centros $(76,0 \%)$ informaram que recebiam recursos do SUS e que esta era sua única fonte de sustento. Os demais recebiam ainda recursos provenientes de consultas particulares, convênios privados e de ONGs internacionais. Esses dados demonstram que o financiamento da atenção a pessoas com anomalias orofaciais no Brasil é, predominantemente público, pelo SUS, e os recursos provêm do Fundo de Ações Estratégicas e de Compensação. Este Fundo foi criado pela Portaria GM/MS no 531, de 30 de abril de 1999 (BRASIL, 1999b), que tem por objetivo garantir o financiamento de ações consideradas estratégicas pelo Ministério da Saúde e a realização de procedimentos de alta complexidade com referência interestadual.

A Política Nacional para Integração da Pessoa Portadora de Deficiência em 1993 (BRASIL, 1993c) também influenciou "o espaço de luta das pessoas com FLP", pois estas apresentam deficiência fonoaudiológica. A publicação do documento da Organização Mundial da Saúde em 2002 foi marco importante (WHO, 2002), e o Brasil também passou a ser signatário dessa política estratégica, beneficiando especificamente as pessoas com algum tipo de anomalia craniofacial.

No caso particular da Bahia, o "espaço social em defesa da pessoa com FLP” era representado pelas ações realizadas pelo Hospital Martagão Gesteira, inaugurado em 1965 e por um setor específico do Hospital Santo Antônio, já mencionado, denominado Centro de Reabilitação e Prevenção de Deficiências (CRPD), fundado em 1992. A Associação de Pais e Amigos dos Fissurados da Bahia (APAF-BA) foi fundada em 1993, ou seja, posterior à fundação do centro, apontando que sua atuação não foi anterior à gênese da intervenção na Bahia. 

no tratamento pediátrico desde os anos 1965, resultado do movimento fundado pela Liga Bahiana Contra a Mortalidade Infantil, liderada pelos pediatras Joaquim Martagão Gesteira, Álvaro da França Rocha e Álvaro Pontes Bahia desde 1923. Este hospital era referência na reabilitação de fissura labiopalatina na Bahia desde os anos 1970 (HMG, 2015). Álvaro Pontes Bahia é membro da família Lopes-Pontes, e Jorge Bahia, cirurgião plástico do Hospital Martagão Gesteira, era primo de irmã Dulce, logo com capital social da família LopesPontes. Assim, observa-se uma rede de relações sociais familiares que também pode estar relacionada à gênese do Centrinho no Hospital de Irmã Dulce.

Outras prováveis razões da ida do serviço para a OSID, e não para o Hospital Martagão Gesteira são trazidas pelo cirurgião-plástico do Centrinho:

\footnotetext{
[...] o pessoal do Centrinho de Bauru tinha uma concepção de atendimento. Era e ainda é, e vai ser sempre um atendimento integral até os 21 anos de idade. O Martagão como hospital pediátrico acompanha o paciente até os 14 anos. Então, eles não quiseram implantar ali [...]. O apoio do Dr. Gastão (Bauru - USP) foi importante, ele era o coordenador de lá na época [...] (Paulo Plessim, cirurgião-plástico do Centrinho desde sua fundação).
}

Cabe destacar, mais uma vez, que o capital simbólico da fundadora da instituição, Irmã Dulce, religiosa importante no campo religioso nacional, teve papel fundamental. Uma fotografia de Irmã Dulce com uma criança com anomalia orofacial em seus braços na entrada do Centrinho, acompanhada da frase "...Muitas vezes, até mesmo cheguei a achar que tudo não dava certo devido meu rosto deformado...” (Um paciente), é um importante exemplo de uso deste capital simbólico.

\section{Algumas das questóes em disputa}

A análise do conjunto de evidências aponta disputas passadas e atuais no papel de cada profissão no tratamento, nos diferentes protocolos para o tratamento no interior do campo médico, especialmente a cirurgia plástica, a ortodontia, a cirurgia bucomaxilofacial e a fonoaudiologia, bem como na disputa em torno do que seria a verdadeira "atenção integral", aqui compreendida como aquela capaz de reabilitar estética, funcional e socialmente o paciente com fissura labiopalatina.

Durante as entrevistas, foram relatadas diversas questóes que permeiam a realidade dos agentes do Centrinho, dentre elas: o alto custo do tratamento 
multidisciplinar, a efetividade e o tempo necessário do tratamento fonoaudiológico, a realização do planejamento da cirurgia em conjunto com a ortodontia e a padronização do protocolo clínico diante da diversidade de opiniōes e exemplos existentes no âmbito nacional e internacional. Os trechos das entrevistas destacados a seguir exemplificam alguns desses aspectos.

Essa perspectiva mais ampla do cidadão gera custos para você reabilitar [...]. Teve outros embates [...]. Tudo que é multidisciplinar evidente que vai causar uma celeuma, que vai causar disputas e tal. E ai tem duas áreas que são hegemônicas, a área médica e a área odontológica. Em Bauru e no Centrinho daqui, essas duas áreas eram sinérgicas, não eram antagônicas. Diferente do que ocorre no plano nacional. No plano nacional há uma disputa. (Túlio Azevedo, médico e coordenador do Centrinho à época da fundação).

[...]. Depois que já fechou o forame e que foi feito todas aquelas cirurgias primárias, o Ortodontista e o Cirurgião dialogam para discutir todo o tratamento juntos. A base para o cirurgião operar é a correção ortodôntica, não se opera o paciente sem correção [...], mas a questão pior não é essa, há profissionais que querem operar sem aparelho. (Maria Conceição Freitas, ortodontista do Centrinho no período de implantação inicial).

Desde que começou o Centrinho lá em Bauru, foi com o Cirurgião Plástico porque se tivesse um bucomaxilofacial competente na época, talvez não procurassem o plástico e sim o bucomaxilo [...] (Roberto Azevedo, cirurgiāo bucomaxilofacial do Centrinho).

A reunião dos serviços para ver a padronização, porque lá na Europa tinha 109 serviços e 123 protocolos diferentes [...] (Paulo Plessim, cirurgião-plástico do Centrinho).

O espaço associativo, como as organizações dos pais e amigos dos "fissurados", também exerce influência nas questôes relacionadas à atenção à pessoa com fissura; no entanto, este aspecto não foi objeto deste estudo. Nos congressos e simpósios relacionados ao "espaço em defesa dos pacientes com FLP", a discussão do melhor protocolo para a reabilitação desses pacientes é um dos temas mais abordados. Apesar de haver associações e estudos internacionais (World Cleft, American Cleft, Euro Cleft, Brasil Cleft e outras) que lutam para unificar as políticas e os protocolos através de documentos, na prática ainda não há unanimidade. $\mathrm{O}$ foco tem sido no alcance de resultados (WHO, 2002; PROFIS, 2009).

Essas disputas internacionais também estão presentes no Brasil, onde a orientação da implantação e funcionamento do serviço de atenção à pessoa com FLP está apenas na portaria de credenciamento ao SUS (BRASIL, 1994), através da qual se exigem equipe mínima, instalações físicas específicas, acompanhamento de dez casos com avaliação documentada e pelo menos cinco 
finalizados, com aspectos estéticos, de aquisição da linguagem e documentação odontológica clínica e cafalométrica.

\section{Discussão}

O enfrentamento da FLP éainda recente no Brasil e está relacionado à consolidação do "espaço de luta", onde os grupos de especialistas parecem exercer maior influência sobre o Estado nessa implementação do que os grupos associativos. Essa característica também foi identificada em políticas de enfrentamento do câncer e da aids na França (PINELL, 2011). Os estudos apontam que as campanhas médicas de curta duração têm sido resposta frequente para enfrentamento parcial do problema em países subdesenvolvidos ou em desenvolvimento (SYKES, 2014), mas sua pequena permanência não é capaz de consolidar uma política específica dos Estados nacionais, em particular (MENDONZA, 2009). É preciso investigar o caso brasileiro, onde a implementação do SUS no início dos anos 1990 configurou uma forma distinta e mais articulada de resposta, possivelmente resultado da influência de agentes interessados na fissura labiopalatina com acúmulo da experiência de Bauru desde os anos 1960, e também do movimento da reforma sanitária brasileira.

A análise das evidências revelou que a criação do Centrinho no Hospital Santo Antônio em Salvador, em 1997, foi resultado de condições de possibilidades concretas de financiamento de alta complexidade iniciado por ato do Estado brasileiro a partir de 1993 (BRASIL, 1993a; 1994; 1999), associados à conjunção de disposiçôes distintas dos diferentes agentes fundadores na Bahia, ou seja, disposiçōes políticas, religiosas, filantrópicas e econômicas, com uso do capital específico de cada um desses agentes (BOURDIEU, 1996; 2014), e do grande capital simbólico acumulado pela fundadora das Obras Sociais Irmã Dulce (OSID), cujo lema da relação entre a caridade e assistência social no Brasil e o campo médico tem sido "amar e servir" (PONTES, 1991; ESCOSIM, 2008).

No serviço de atenção à pessoa com fissura labiopalatina, coexistem especialistas na reabilitação, como cirurgiões plásticos, cirurgiōes-dentistas de diversas especialidades, fonoaudiólogos e assistentes sociais. Isso configura uma disputa importante sobre a definição das fronteiras que delimitam o exercício profissional nesse espaço social, dominado por tantas especialidades, saberes e práticas. Além disso, a presença de pesquisadores, gestores federais e gestores 
do centro, bem como pacientes e seus familiares, que pertencem a campos distintos, torna a análise desse espaço em particular mais complexa. Há indícios do predomínio do campo médico neste subespaço, com o polo dominante da cirurgia plástica, que corroboram a existência de disputas políticas e científicas trazidas pela literatura (SHAW et al., 2005; PROFIS, 2009).

No que concerne ao enfrentamento das anomalias orofaciais e da FLP, podese afirmar que no Brasil existe uma resposta social estatal, expandida a partir de 1993, mas pode-se considerar essa resposta social ainda frágil. A falta de diretrizes oficiais dessa política contribui para que o espaço social em defesa das pessoas com fissura labiopalatina no país não tenha um discurso universal, e isso mantém forte as disputas políticas e científicas (PROFIS, 2009). O conceito de reabilitação é disputa importante, na medida em que a reabilitação social do paciente com fissura exige maior poder às áreas atualmente "dominadas", como é o caso da fonoaudiologia e ortodontia. A diversidade de protocolos e práticas assistenciais no âmbito internacional (MONLLEÓ, 2004; SHAW et al., 2001) tem motivado iniciativas para o estabelecimento de padrões de funcionamento dos serviços de atenção à FLP, sobretudo pelos Estados Unidos (ACPA, 2009) e Europa (SANDY et al., 1998; WHO, 2002).

A partir das evidências do presente estudo exploratório, o Centrinho de Salvador parece seguir o protocolo de tratamento multidisciplinar, desenvolvido pelo Centrinho de Bauru, São Paulo. Contudo, há indícios de problemas na sua implantação, como a ausência de busca ativa dos casos, que pode comprometer o sucesso da reabilitação, necessitando ser mais bem compreendida em estudos sobre sua implantação.

\section{Considerações finais}

A análise a partir do referencial teórico explicativo de Pierre Bourdieu e Patrice Pinel revelou que a emergência do Centrinho baiano esteve associada, sobretudo, às disposições políticas, religiosas, filantrópicas e econômicas dos agentes fundadores, e do grande capital simbólico acumulado pela fundadora das Obras Sociais, Irmã Dulce. Apesar de não contemplar a dinâmica das posições dos agentes de diferentes espaços sociais no decorrer da implementação do Centrinho, o presente estudo, por seu caráter exploratório, forneceu algumas hipóteses a serem aprofundadas em estudos posteriores. 
Estudos sócio-históricos que investiguem em profundidade o caso nacional desde a fundação do Centrinho de Bauru nos anos 1960 são recomendados. A análise das principais questôes em disputa envolvidas na emergência e implementação dessa política no Brasil podem colaborar na construção de um possível discurso oficial universal do Estado, capaz de promover uma resposta social mais consolidada e produtora de uma atenção e reabilitação integral aos pacientes com fissura labiopalatina no país. ${ }^{1}$

\section{Referências}

AMERICAN Cleft Palate-Craniofacial Association. Parameters for evaluation and treatment of patients with cleft lip/palate or other craniofacial anomalies. Revised Edition November, 2009, 34p.

AQUINO, S.N. et al. Study of patients with cleft lip and palate with consanguineous parents. Braz. J. Otorhinolaryngol. São Paulo, v. 77, n. 1, jan./fev. 2011, p. 19-23.

BOURDIEU, P. Razões práticas: sobre a teoria da ação. $6^{a}$ ed. Campinas: Papirus, 1996.

BOURDIEU, P. Sobre o Estado: cursos no Collège de France (1989-92). $1^{\text {a }}$ Ed. São Paulo: Cia das Letras, 2014.

BOYLES, A.L. et al. Maternal alcohol consumption, alcohol metabolism genes, and the risk of oral clefts: a population-based case-control study in Norway, 1996-2010. Am J Epidemiol. v. 172 , n. 8 , out. 2010 , p. $924-931$.

BRASIL. Lei no 8080, de 19 de setembro de 1990. Dispõe sobre as condições para proteção e recuperação da saúde, a organização e funcionamento dos serviços correspondentes e dá outras providências. Brasília, Diário Oficial da República Federativa do Brasil, Brasília, DF. 19 set. 1990.

-----. Decreto no 3.298, de 20 de dezembro de 1999. Regulamenta a Lei no 7.853, de 24 de outubro de 1989, dispõe sobre a Política Nacional para a Integração da Pessoa Portadora de Deficiência, consolida as normas de proteção, e dá outras providências. Diário Oficial da República Federativa do Brasil. Brasília, DF. 21 dez. 1999a.

-----. Decreto no 914, de 06 de dezembro de 1993. Institui a Política Nacional para a Integração da Pessoa Portadora de Deficiência, e dá outras providências. Diário Oficial da República Federativa do Brasil. Brasília, DF. 06 dez. 1993c.

------ Lei n. 8.742, de 7 de dezembro de 1993.Dispõe sobre a organização da Assistência Social e dá outras providências. Diário Oficial da República Federativa do Brasil, Brasília, DF. 7 dez. 1993a. 
(SINASC) para fissuras labiopalatinas. Disponível em: http://tabnet.datasus.gov.br/cgi/ deftohtm.exe? sinasc/cnv/nvuf.def. Acesso em: 8 jan. 2013.

-----. Portaria GM/MS no 531, de 30 de abril de 1999. Define os recursos federais destinados ao financiamento das ações e serviços de saúde, que compõem o Teto Financeiro da Assistência à Saúde dos estados e do Distrito Federal, constantes do Anexo I desta Portaria, integrado por recursos para Atenção Básica e para Assistência Ambulatorial, de média e alta complexidade e Hospitalar. Diário Oficial da República Federativa do Brasil, Brasília, DF, 1999b.

-----. Portaria SAS/MS n. 126, de 17 de setembro de 1993. Cria grupos e procedimentos para tratamento de lesões labiopalatais na tabela SIH/SUS, e dá outras providências. Diário Oficial da República Federativa do Brasil. Brasília, DF. 21 set. 1993b.

-----. Portaria SAS/MS n. 62, de 19 de abril de 1994. Normaliza cadastramento de hospitais que realizem procedimentos integrados para reabilitação estético-funcional dos portadores de má-formação labiopalatal para o Sistema Único de Saúde, e dá outras providências. Diário Oficial da Uniāo, Brasília, DF. 20 abr. 1994.

. Secretaria de Atenção à Saúde. Relatório de Gestão 2015. Brasília, DF. Março 2016. Disponível em: http://portalsaude.saude.gov.br/index.php/relatorios-de-gestao Acesso em: 20/05/16.

DI NINNO, C.Q.M.S.et al. Prevalência de fissura de palato submucosa associada à fissura labial. Rev. Soc. Bras. Fonoaudiol. São Paulo, v. 16, n.3, jul./set. 2011, p. 304-9.

ESCORSIM, S.M. A filantropia no Brasil: entre a caridade e a politica de assistência social. Revista Espaço Acadêmico (UEM) 2008. Disponível em: <http://www.espacoacademico. com.br/086/86escorsim.htm>. Acesso em: 20 de janeiro de 2014.

HOSPITAL Martagão Gesteira. Disponível em:<http://www.martagaogesteira.org.br/ Pagina.aspx?pagina=nossa-historia $>$. Acesso em: 23 jan. 2015.

HOROVITZ, D.D.G.; LLERENA-JR, J.C.; MATTOS, R.A. Atenção aos defeitos congênitos no Brasil: panorama atual. Cad. Saúde Pública. Rio de Janeiro, v. 21, n. 4, jul./ ago. 2005, p.1055-1064.

HOSPITAL de Reabilitação de Anomalias Crâniofaciais da Universidade de São Paulo. Disponível em:<www.usp.br/jorusp/arquivo/2004/jusp697/pag08.htm>. Acesso em: 08. jan. 2014.

MARTELLI, D.R.B. et al. Avaliação da idade materna, paterna, ordem de paridade e intervalo interpartal para fissura lábio-palatina.Braz J Otorhinolaryngol. São Paulo, v. 76, n. 1, fev. 2010, p.107-12. 

a pacientes portadores de fissuras labiopalatinas. J. Bras. Ortodon. Ortop. Facial, v. 7, n. 37, p. 23-32, 2002.

MENDOZA, R.L. Public Health Policy and Medical Missions in the Philippines: The Case of Oral-Facial Clefting. Asia-Pacific Journal of Public Health. v. 21, n. 1, p. 94-103, 2009.

MONLLEÓ, I.L.; GIL-DA-SILVA-LOPES, V.L. Anomalias craniofaciais: descrição e avaliação das características gerais da atenção no sistema único de saúde. Cad Saúde Pública. Rio de Janeiro, v. 22, n. 5, maio 2006, p. 913-922.

MURRAY, J.C. et al. Clinical and epidemiologic studies of cleft lip and palate in the Philippines. CleftPalateCraniofac. J. Lewiston, v. 34, n. 1, p. 7-10, jan. 1997.

OBRAS Sociais Irmã Dulce. Disponível em: <http://www.irmadulce.org.br/obrassociais/ saude_centrinho.php>. Acesso em: 15 jun.2014.

PINELL, P. Análise sociológica das políticas de saúde. Rio de Janeiro: Fiocruz, 2011.

PONTES, M.R. Irmã Dulce dos Pobres. 13a edição. Rio de Janeiro: Sindicato Nacional, 1991.

PROFIS. IX Encontro Nacional de Associaçôes de pais e pessoas com lesóes labiopalatinas el ou deficiências auditivas e V Encontro da Rede Profis. Sociedade de Promoção Social do Fissurado Lábio - Palatal. Carta de Bauru. 2009. Disponível em: <www.redeprofis.com. br>. Acessoem: 20 jan. 2014.

SANDY, J. R. et al. Cleft lip and palate care in the United Kingdom - The Clinical Standards Advisory Group (CSAG) Study: part 1 - background and methodology. Cleft Palate CraniofacJ, v. 38, 2001, p. 20-3.

SHAW, W.C. et al. The Eurocleft Project 1996-2000: overview. Journal of Cranio Maxillofacial Surgery, v. 29, 2001, p. 131-140.

.The Eurocleft study: intercenter study of treatment outcome in patients with complete cleft lip and palate. Part 5: discussion and conclusions. Cleft Palate Craniofac J. v. 42, n. 1, 2005, p. 93-8.

SOUZA, C.M.C.; BARRETO, M.R.N. História da saúde na Bahia: instituições e patrimônio arquitetônico (1808-1958). São Paulo: Manoele, 2011.

SOUZA-FREITAS, J.A.et al. Tendência familial das Fissuras labiopalatinas. $R$ Dental Press OrtodonOrtop Facial.Maringá, v.9, n.4, jul./ago. 2004, p.74-78.

STOLL, C.; CLEMENTI, M. Euroscan Study G. Prenatal diagnosis of dysmorphic syndromes by routine fetal ultrasound examination across Europe.Ultrasound in Obstetrics \& Gynecology, v. 21, n. 6, may. 2003, p. 543-51.

SYKES, K.J. Short-term medical service trips: a systematic review of the evidence. American Journal of Public Health, v. 104, n. 7; July 2014; p. 38-48. 
WEHBY, G.L.; CASSELL, C.H.The impact of orofacial clefts on quality of life and healthcare use and costs.Oral Diseases. v. 16, n. 1, jan. 2010, p. 3-10.

WORD Health Organization. Global strategies to reduce the health-care burden of craniofacial anomalies. Geneva: WHO, 2002.

\section{Notas}

${ }^{1}$ S.C.L. Chaves: formulou o projeto de pesquisa, coletou e analisou os dados e redigiu o manuscrito final. L.C.M. da Silva realizou coleta de dados, participou das etapas de formulação e análise dos dados e redação final. A.M.F. de L. Almeida participou da análise dos dados, formulação e revisão final do manuscrito. 
Oral and palate cleft policy: the emergence of the Centrinho of Salvador, Bahia, Brazil The emergence of coping with cleft lip and palate in Bahia between 1990 and 2000 was analyzed through an emergency exploratory study of the Rehabilitation Center of Cleft Lip and Palate of Bahia, Brazil (known as Centrinho), using the analysis of social space, agents and their capital, according to Bourdieu (2014). Semistructured interviews, and analyzes of reports and official documents were conducted. The study revealed that the creation of the Centrinho allowed high-complexity financing associated with the combination of different provisions of different founders agents. In this space, experts in rehabilitation and disputes over the definition of what is a comprehensive care to people with cleft lip and palate coexist.

Key words: cleft lip; cleft palate; health policy; health history; public health. 